\title{
BMJ Open Impact of the zero-mark-up drug policy on drug-related expenditures and use in public hospitals, 2016-2018: an interrupted time series study in Shaanxi
}

\author{
Kangkang Yan, ${ }^{1,2}$ Caijun Yang (D) , ${ }^{1}$ Hongli Zhang, ${ }^{3}$ Dan $Y e,{ }^{2}$ Shengyuan Liu, ${ }^{2}$ \\ Jie Chang, ${ }^{1}$ Minghuan Jiang, ${ }^{1}$ Mingyue Zhao, ${ }^{1}$ Yu Fang ${ }^{1}$
}

To cite: Yan $\mathrm{K}$, Yang $\mathrm{C}$, Zhang $\mathrm{H}$, et al. Impact of the zero-markup drug policy on drug-related expenditures and use in public hospitals, 2016-2018: an interrupted time series study in Shaanxi. BMJ Open 2020;10:e037034. doi:10.1136/ bmjopen-2020-037034

- Prepublication history for this paper is available online. To view these files, please visit the journal online (http://dx.doi. org/10.1136/bmjopen-2020037034).

Received 24 January 2020 Revised 30 June 2020 Accepted 16 August 2020

D) Check for updates

(C) Author(s) (or their employer(s)) 2020. Re-use permitted under CC BY-NC. No commercial re-use. See rights and permissions. Published by BMJ.

1Department of Pharmacy Administration and Clinical Pharmacy, School of Pharmacy, Xi'an Jiaotong University, Xi'an, China

${ }^{2}$ Department of Pharmacy, Xi'an No. 3 Hospital, the Affiliated Hospital of Northwest University, Xi'an, China

${ }^{3}$ Department of Pharmacy, Xi'an Central Hospital, Xi'an, China

Correspondence to

Professor Yu Fang;

yufang@mail.xjtu.edu.cn

\section{ABSTRACT}

Objective The aim of this study was to measure the impact of zero-mark-up drug policy (ZMDP) on drugrelated expenditures and use in urban hospitals.

Design This was a retrospective observational study of trends in drug expenses and use in the context of the ZMDP using an interrupted time series analysis.

Setting Twelve hospitals (three tertiary hospitals and nine secondary hospitals) in Xi'an, which is the capital of Shaanxi Province in Western China.

Data and participants The prescription information for all outpatients and inpatients in the study hospitals from January 2016 to April 2018 was used in this study. Interventions The Chinese government announced the policy intervention measure of the ZMDP, which was implemented in all public hospitals as of 1 April 2017.

Primary measures Monthly drug expenditures, monthly medical expenditures, the percentage of drug expenditures among total medical expenditures, the average outpatient drug expenditure per visit, the percentage of prescriptions that include an injection and the percentage of prescriptions that include an antibiotic.

Results Monthly total medical expenses increased in both tertiary and secondary hospitals after the ZMDP was implemented. In tertiary hospitals, the average outpatient drug expenditures per visit showed a slow decreasing trend before the intervention and an increasing trend after the intervention, with statistically significant changes in both the level $(p<0.001)$ and the trend $(p=0.02)$. Secondary hospitals showed a slow increasing trend both before and after the policy implementation, with no significant change in the trend $(p=0.205)$. The proportion of prescriptions, including injections, was over $20 \%$ in secondary hospitals and less than $20 \%$ in tertiary hospitals, with no significant changes to this indicator observed after implementation of ZMDP.

Conclusions The effect of the ZMDP on drug-related expenditures and use in Chinese public hospitals was not substantially evident. Future pharmaceutical reform measures should give more consideration to physician prescription behaviours.

\section{INTRODUCTION}

Rational drug use refers to patients receiving medicines that are clinically suitable for them
Strengths and limitations of this study

- We aimed to explore the long-term effects of the zero-mark-up drug policy (ZMDP) on drug-related expenditures and use in urban public secondary and tertiary hospitals in China.

- This study used interrupted time series analysis to evaluate the longitudinal effects of the ZMDP intervention.

- The results may not reflect the effects of the ZMDP intervention throughout China.

and that meet their individual needs for an adequate period of time and at the lowest cost to both them and their community. ${ }^{1}$ However, the inadequate use of beneficial, cost-effective drugs and the overuse of unnecessary drugs are common in medical institutions around the world. ${ }^{2}$ It has been estimated that of all the medications prescribed, dispensed or sold worldwide, more than $50 \%$ are inappropriate. ${ }^{3}$ Irrational drug use is a serious problem in China, as it is in other countries. A systematic review analysing the irrational use of medicines in China between 1993 and 2013 found that the proportions of antibiotics and injections prescribed per 100 encounters were $41 \%-60 \%$ and $21 \%-60 \%$, respectively. ${ }^{4}$

The potential adverse effects of irrational drug use include increased adverse drug reactions, drug resistance (such as antibiotic resistance), prolonged duration of treatment, increased treatment costs and increased mortality. ${ }^{5}$ It is estimated that there will be $\$ 100$ trillion in costs and 10 million deaths annually worldwide by 2050 if substantive efforts are not made to curb the threat of bacterial resistance,${ }^{6}$ which is associated with the widespread and irrational use of antimicrobial agents. ${ }^{7}$ A retrospective analysis of clinical pharmacy team interventions found, net medical cost savings of $\$ 428327$ for 
such interventions, with most pharmacist interventions $(53 \%)$ being classified as in the area of drug treatment, $21 \%$ being classified as in the area of quality and safety improvement, and $18 \%$ related to antibiotic management. ${ }^{8} \mathrm{~A}$ recent systematic review found that the irrational use of medicines in China was serious and resulted in unnecessary polypharmacy and the overuse of antibiotics and injections. ${ }^{4}$

A 15\% mark-up charged by public hospitals over wholesale drug prices was historically considered the main cause of medication overuse in China. This was known as the 'mark-up policy' and was introduced in 1978 to counterbalance balance the government's significantly reduced financial annual subsidies to public hospitals. ${ }^{9-11}$ With this policy, drug sales became a major revenue source for hospitals and physicians. Inevitably, more drugs than were needed and drugs with higher profit margins were prescribed by physicians for financial incentives, and this became a well-known problem in China. ${ }^{12} 13$ The proportion of drug sales as a percentage of the total income remained high (over 40\%) between 1990 and 2009. ${ }^{14}$ Drug expenditures per outpatient visit grew rapidly from 10.9 RMB to 146.5 RMB between 1990 and 2008, exceeding the growth rate of the gross domestic product (GDP) over the same period. ${ }^{15}$

To discourage public hospitals from profiting from overprescription and to keep healthcare affordable, the Chinese government issued a new round of health system reforms in August 2009. The core component of this reform was the gradual elimination of the additional drug mark-up in public hospitals. This was known as the zero mark-up drug policy (ZMDP) ${ }^{16}$ and it is implemented at different stages in different provinces. ${ }^{17}$ In most of provinces, the implementation of ZMDP was instituted in three principal phases. First, the policy was implemented in primary healthcare institutions including township health institutions and village clinics beginning in 2009 and in all primary health institutions by the end of 2011. Second, the policy was implemented in all county hospitals by the end of 2015. Finally, the ZMDP was extended to all other public hospitals on 1 April 2017.

Several studies have evaluated the achievements of the ZMDP reform. Most of these studies have focused on health service utilisation, medical expenditure and the affordability of medicine. For example, Tao $e t a l^{18}$ found that the outpatient provision of care increased by $25 \%$ after the implementation of the ZMDP. Jin et $a l^{19}$ also found that this policy increased the provision of care in township hospitals and community healthcare centres. Yang $e t a l^{20}$ found that the ZMDP significantly reduced average monthly hospitalisation expenditures as well as average monthly hospitalisation expenditures after reimbursement at county hospitals in Shaanxi Province. Wei et $a l^{21}$ showed that the medication costs per visit were significantly reduced 1 year after the ZMDP was implemented. Wang et $a l^{22}$ showed that changes in medication and healthcare charges were associated with the hospital's level. However, most studies of the ZMDP reform have focused on primary healthcare institutions and county hospitals, with only a small number of studies examining tertiary hospitals. $^{23-25}$

Moreover, studies assessing the impact of the ZMDP on drug use have also focused primarily on primary healthcare institutions, with less attention being paid to tertiary or secondary institutions. Wei $e t a l^{26}$ investigated the impact of the ZMDP on antibiotic prescription behaviour in rural Guangxi and found that the policy may reduce in outpatient antibiotic prescribing and intravenous infusions when implemented along with an antimicrobial stewardship programme. Mao et $a l^{25}$ analysed changes in drug use patterns at different medical institutions in Hangzhou after the implementation of the ZMDP and found that the average number of medications per prescription, the average number of antibiotics per prescription and the average number of injections per prescription all declined. More empirical studies are needed to understand the impact of the ZMDP on drugrelated use and drug expenditure, especially in other parts of China outside of Hangzhou. Promoting rational drug use and reducing the medical burden on patients is the ultimate goal of 'separating drug sales from hospitals' other services', which is a core component of drug policy reform; thus, it is essential to understand the effects of the ZMDP on drug-related use for patients in Western China's urban public hospitals.

\section{Aim of the study}

The objective of this study, therefore, was to measure the effects of the ZMDP on drug-related use and expenses in urban public secondary and tertiary hospitals.

\section{METHODS}

\section{Study design}

A quasiexperimental interrupted time series analysis was conducted covering every month continuously for an overall period of 28 months, comprising the first 15 months before the policy was implemented (January 2016 to March 2017) and the first 13 months after policy implementation (April 2017 to April 2018). The interrupted time series design is regarded as the strongest quasiexperimental approach for evaluating longitudinal effects of interventions. ${ }^{27} 28$ The segmented regression analysis of interrupted time series data can compare variations in outcomes before and after the intervention and can determine whether there is a statistical correlation between the intervention and any observed changes in outcomes. ${ }^{27}$

Our study was conducted in Shaanxi Province, which is broadly representative of the typical health system and population health profile of the 12 western provinces of China. Shaanxi Province is also an important hub of the Belt and Road Initiative and a major pilot province for Western health system reform in western China. All the urban public hospitals in Shaanxi Province were implemented the ZMDP on 1 April 2017. 
Hospital compensation was changed from three channels of medical service charges, drug markup income and government subsidies to two channels of medical service charges and government subsidies. The reasonable income reduced by the elimination of the drug mark-up, and $90 \%$ will be compensated according to the adjustment of medical service price, $5 \%$ will be compensated by the financial department at the same level, and $5 \%$ will be shared by the hospital to strengthen cost accounting. Xi'an city was selected as our sample city based on the following considerations. Xi'an, which is the capital city of Shaanxi Province, had the second highest GDP per capita in 2016 among a sample of 10 cities. ${ }^{29}$ It has a population of 8249300 and an area of $10096.81 \mathrm{~km}^{2}$, and it is one of the largest inland cities in Western China. ${ }^{29}$ All the public hospitals in Xi'an had established a comprehensive electronic medical records system before 2015 ; thus, we were easily obtained data for our analyses.

\section{Sample size and data source}

A quota sampling method was used to identify target hospitals. We searched the official website of the Shaanxi Health Commission and determined that there were a total of 75 secondary hospitals and 26 tertiary hospitals, for a ratio of approximately $3: 1 .^{29}$ We also considered the degree of cooperation between the hospitals and our study team, and the availability of data on indicators during the study period (2016-2018). Secondary and tertiary hospitals were chosen based on the following considerations: (1) general public hospitals (excluding specialist hospitals); (2) hospitals with similar total numbers of outpatients and inpatients per year and (3) a hospital dean who agreed to take part in this study. We then randomly selected 3 tertiary hospitals and 9 secondary hospitals, for a total of 12 sampled hospitals for the study.

Data on the outcome variables were collected from hospital electronic medical records systems. Two investigators were assigned to enter the data on separate forms to ensure data accuracy.

\section{Indicators}

Indicators were selected based on recommendations of the WHO/International Network for the Rational Use of Drugs (WHO/INRUD), combined with information about the specific situation in China and data availability. Six final indicators were included in the analyses: monthly drug expenditures; the monthly medical expenditures; the percentage of drug expenditures to total medical expenditure; the average outpatient drug expenditures per visit; the percentage of prescriptions that include injection and the percentage of prescriptions that include an antibiotic. The first four indicators reflect drug-related expenditures on patients, whereas the last two reflect the use of drugs. We hypothesised that the ZMDP would promote rational drug use in hospitals and would reduce the burden of prescription drug use among patients, that is, all the indicators would be reduced significantly after implementation of the ZMDP.

\section{Data analysis}

A segmented regression model with one intervention point was specified as follows:

$Y_{t}=\beta_{0}+\beta_{1}$ time $+\beta_{2}$ intervention $+\beta_{3}$ time after intervention $+e_{t}$

where $Y_{t}$ is the outcome variable at time $t$; time is a continuous variable indicating the number of months from the start of the observation period; intervention is an indicator for the occurrence of time $t$ before (intervention=0) or after (intervention=1) implementation of the ZMDP; time after intervention is a continuous variable indicating the number of months from the start of the intervention that is equal to 0 (time before intervention) or $(t-15)$ (time after intervention); $\beta_{0}$ estimates the baseline level of the outcome before the intervention (time $=0$ ); $\beta_{1}$ estimates the change in the outcome occurring with each period before the intervention, namely the baseline trend; $\beta_{2}$ estimates the change in the outcome after the intervention, compared with the level at the end of the preceding segment; and $\beta_{3}$ estimates the change in the trend for the outcome after implementation of the ZMDP compared with the monthly trend in the preceding segment, where the trend represents the rate of change of the outcome variable, namely, the slope. Finally, $e_{t}$ refers to the error term at time $t$.

We used the Durbin-Watson test to check for autocorrelation and modified the model according to the test results. The Dickey-Fuller statistic was used to test for seasonal fluctuation. Based on expert consensus, an indicator variable for seasonality was set to 0 for the months of January, February, March, October, November and December, and to 1 for all other months. All data were entered and verified using Excel V.2007 and were analysed using STATA V.12.0. The data were analysed and presented separately for secondary and tertiary hospitals. $\mathrm{P}<0.05$ was considered statistically significant.

\section{Ethical statement}

This study was approved by the Xi'an Jiaotong University Health Science Center, the Shaanxi Provincial Health Commission, the Shaanxi Food and Drug Administration, and all participating hospitals prior to data collection. The dean of each hospital gave verbal consent for participation in the study. The requirement for patient consent was waived because the study involved no contact with patients and all the patient information was anonymous.

\section{Patient and public involvement}

In this research, we only included the medication information of patients and all the information was anonymous. Neither patients nor the public were involved in this research. 


\section{RESULTS}

From January 2016 to April 2018, there was an average of 855 open beds in each tertiary hospital and 290 open beds in each secondary hospital.

\section{Percentage of drug expenditures among total medical expenditures}

As shown in figure 1, there was a slow decreasing trend both before and after the implementation of the ZMDP, and no obvious level or trend change was observed. There was a non-significant decrease $\left(\beta_{2}=-0.012, \mathrm{p}=0.130\right)$ in the intercept in tertiary hospitals after the intervention (table 1).

No significant trend fluctuations were found in the percentage of drug expenditures to total medical expenditures in secondary hospitals before the intervention. After the intervention, the level changed suddenly but the trend did not fluctuate (figure 1). A significant decline $\left(\beta_{2}=-0.031, \mathrm{p}=0.002\right)$ was observed in the intercept after the intervention in secondary hospitals (table 1 ).

\section{Monthly drug expenditures and medical expenditures}

There was no significant change in drug expenditures before or after the intervention in either tertiary or

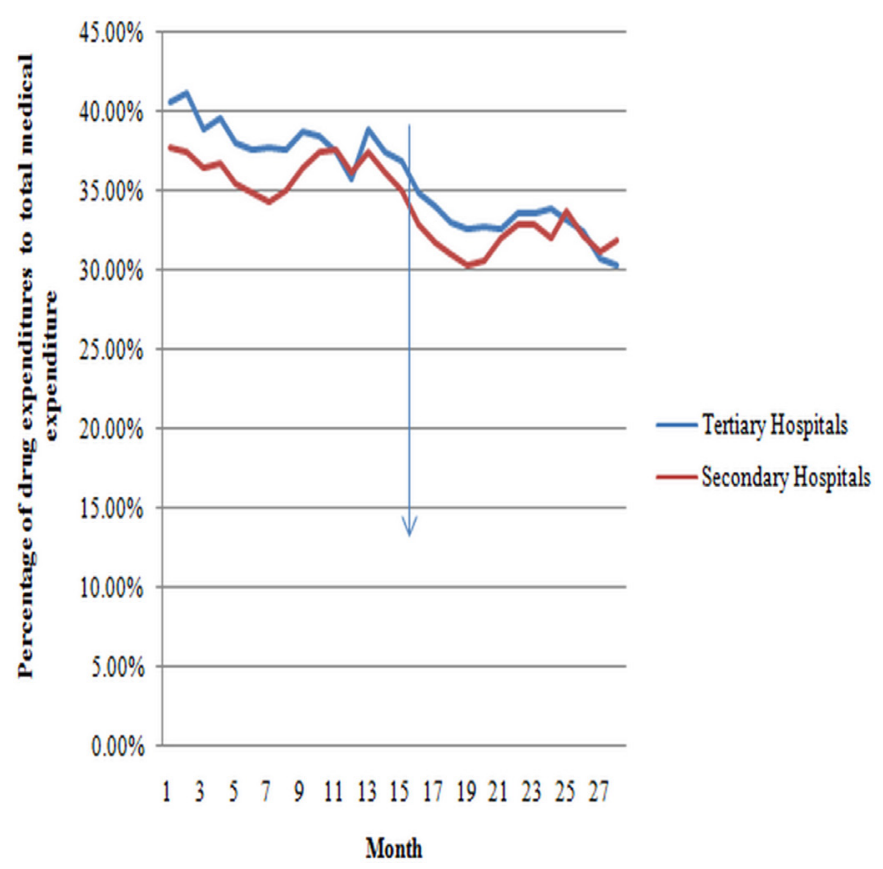

Figure 1 Change of the percentage of drug expenditures to total medical expenditure from January 2016 to April 2018.

Table 1 The impact of the implementation of the zero-mark-up policy on rational drug use in hospitals

\begin{tabular}{|c|c|c|c|c|}
\hline \multirow[b]{2}{*}{ Indicators } & \multicolumn{2}{|c|}{ Secondary hospitals } & \multicolumn{2}{|c|}{ Tertiary hospitals } \\
\hline & Coefficient & $P$ value & Coefficient & P value \\
\hline \multicolumn{5}{|c|}{ Percentage of drug expenditures to total medical expenditures } \\
\hline$\beta_{1}$ & -0.001 & 0.192 & -0.003 & 0.000 \\
\hline$\beta_{2}$ & -0.031 & 0.002 & -0.012 & 0.130 \\
\hline \multicolumn{5}{|c|}{ The average outpatient expenditure per visit } \\
\hline$\beta_{0}$ & 115.059 & 0.000 & 138.236 & 0.000 \\
\hline$\beta_{1}$ & 0.394 & 0.205 & -1.630 & 0.000 \\
\hline$\beta_{2}$ & -7.668 & 0.086 & -12.378 & 0.020 \\
\hline \multicolumn{5}{|c|}{ Percentage of prescriptions that include an injection } \\
\hline$\beta_{0}$ & 0.280 & 0.000 & 0.134 & 0.000 \\
\hline$\beta_{1}$ & -0.004 & 0.000 & 0.0002 & 0.896 \\
\hline$\beta_{2}$ & 0.044 & 0.000 & 0.029 & 0.203 \\
\hline$\beta_{3}$ & 0.001 & 0.684 & -0.005 & 0.084 \\
\hline Season & - & - & -0.033 & 0.000 \\
\hline \multicolumn{5}{|c|}{ Percentage of prescriptions that include an antibiotic } \\
\hline$\beta_{0}$ & 0.264 & 0.000 & 0.120 & 0.000 \\
\hline$\beta_{1}$ & -0.004 & 0.000 & -0.001 & 0.058 \\
\hline
\end{tabular}




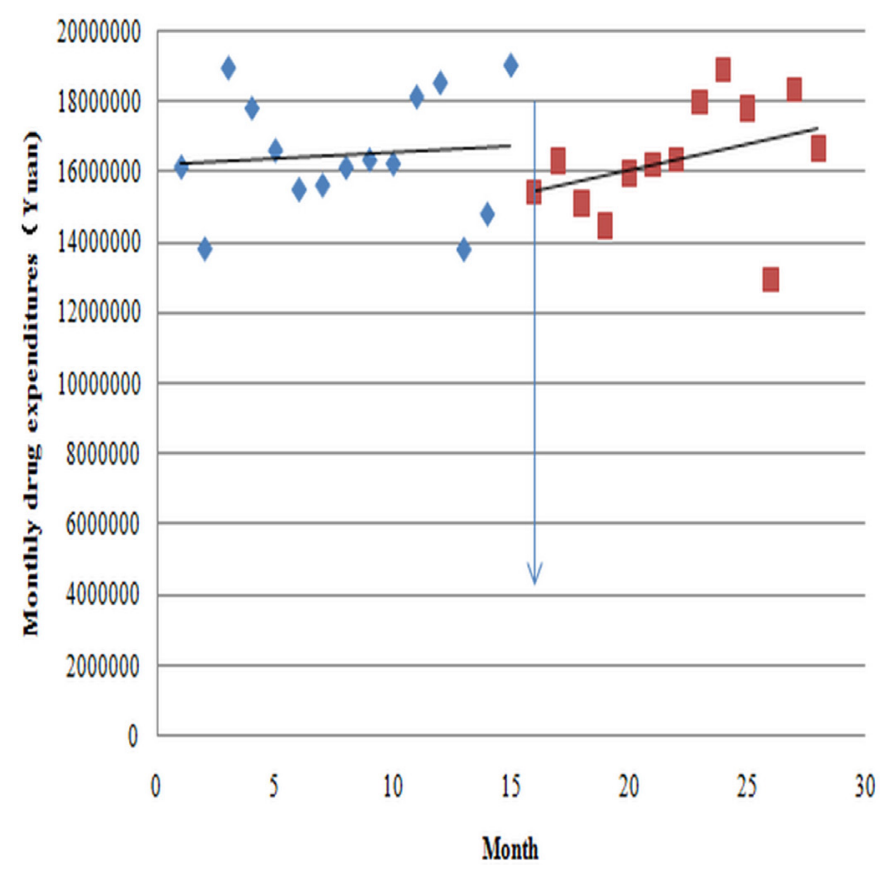

Figure 2 Change of the monthly drug expenditures in tertiary hospitals from January 2016 to April 2018.

secondary hospitals, but the total medical expenses increased after the intervention in both types of hospitals (details are shown in figures 2-5).

\section{Average outpatient drug expenditure per visit}

In tertiary hospitals, the average outpatient drug expenditure per visit showed a decreasing trend before the intervention (figure 6). After the implementation of the ZMDP, the average outpatient drug expenditure per

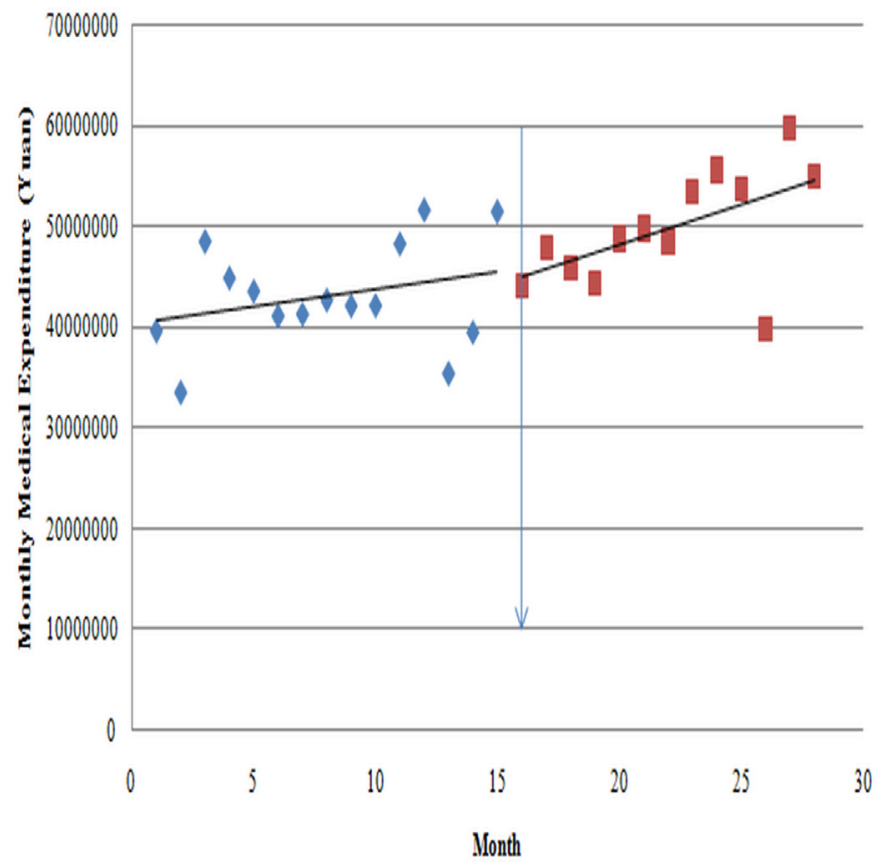

Figure 3 Change of the monthly medical expenditure in tertiary hospitals from January 2016 to April 2018.

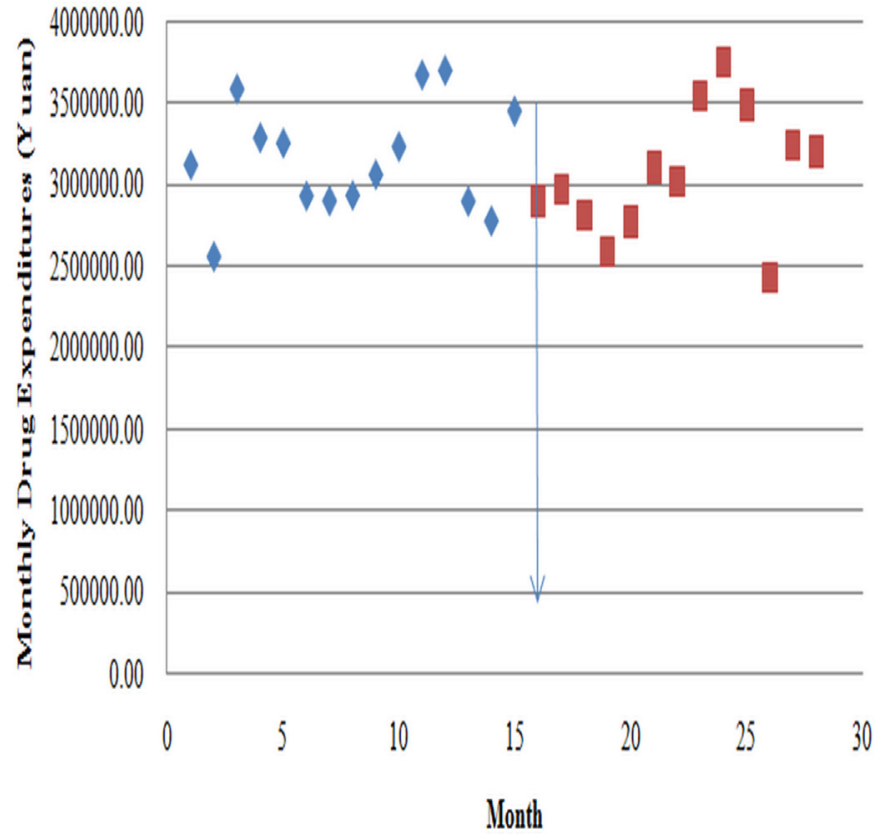

Figure 4 Change of the monthly drug expenditures in secondary hospitals from January 2016 to April 2018.

visit decreased sharply $\left(\beta_{2}=-12.378, \mathrm{p}=0.020\right)$ with an increasing trend $\left(\beta_{3}=4.399, \mathrm{p}<0.001\right)$.

In secondary hospitals, the average outpatient drug expenditure per visit showed a non-significant increase before the intervention (figure 6). After the intervention, the average outpatient drug expenditures per visit decreased $\left(\beta_{2}=-7.668, \mathrm{p}=0.086\right)$, and an increasing trend was observed $\left(\beta_{3}=0.617, \mathrm{p}=0.212\right)$, although neither of these findings were statistically significant.

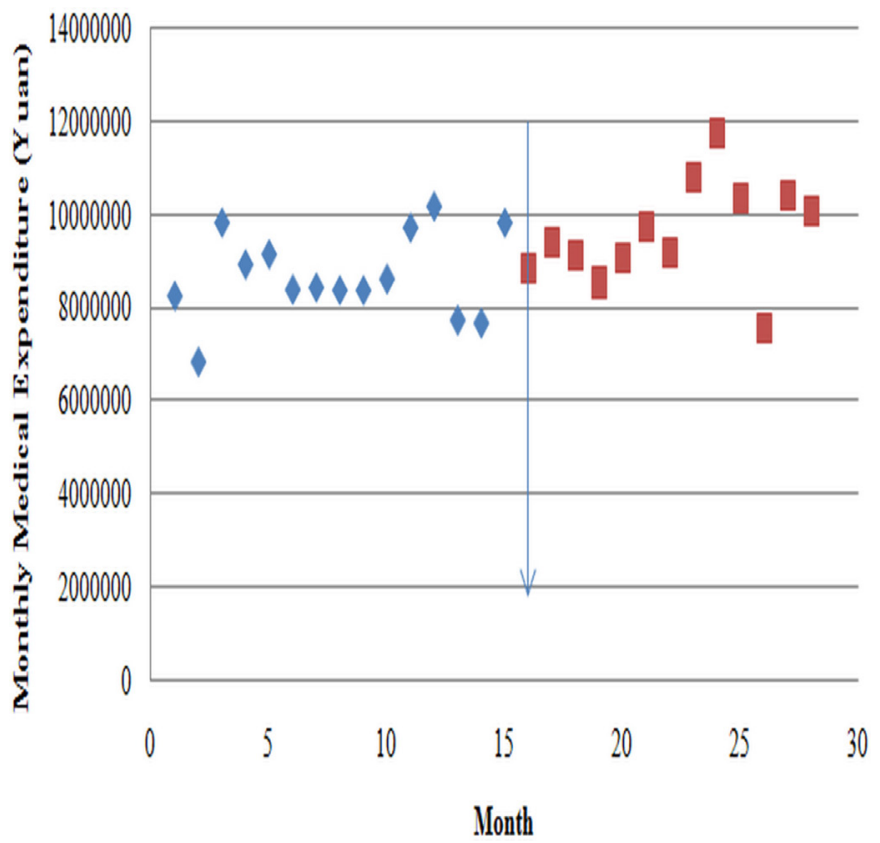

Figure 5 Change of the monthly medical expenditure in secondary hospitals from January 2016 to April 2018. 


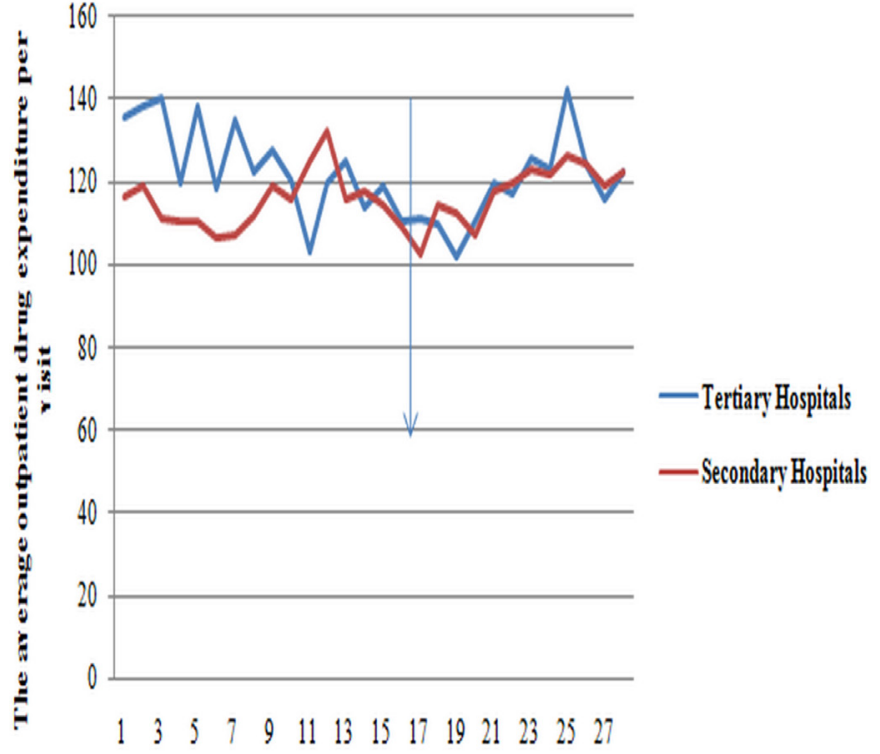

Month

Figure 6 Change of the average outpatient drug expenditure per visit from January 2016 to April 2018.

\section{Percentage of prescriptions that include an injection}

Seasonal variation was found in the percentage of prescriptions that include an injection in tertiary hospitals, with the highest usage rates seen in the fourth quarter of each year (figure 7 ). No significant change was detected in the level $\left(\beta_{2}=0.029, \mathrm{p}=0.203\right)$ or the trend $\left(\beta_{3}=-0.005\right.$, $\mathrm{p}=0.084$ ) of this indicator in tertiary hospitals.

In secondary hospitals, the percentage of prescriptions that include an injection did not fluctuate seasonally but rather showed a slow downward trend before the

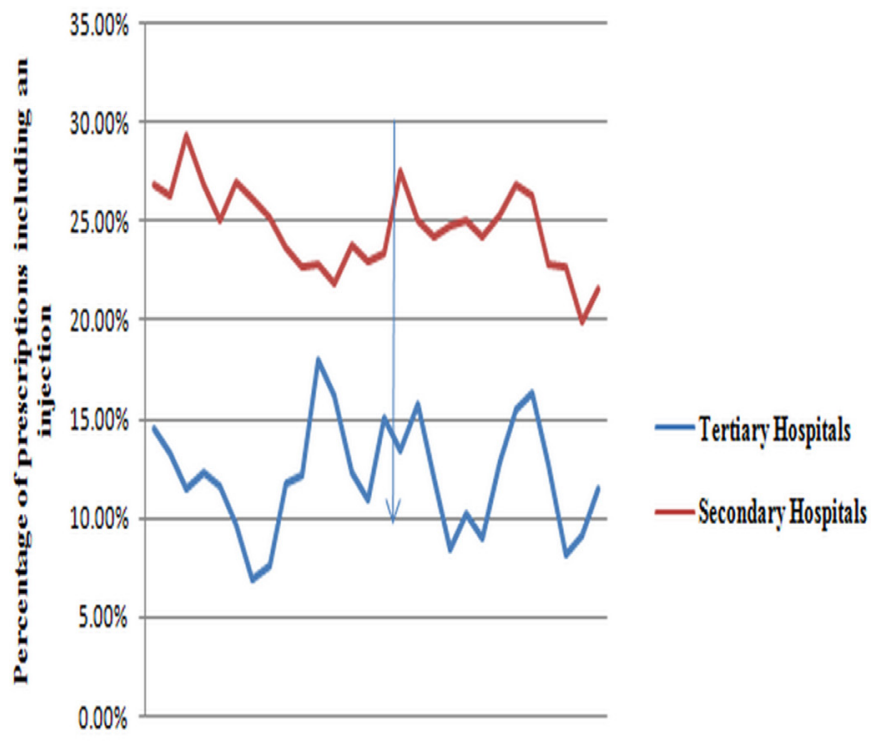

$\begin{array}{llllllllllllll}1 & 3 & 5 & 7 & 9 & 11 & 13 & 15 & 17 & 19 & 21 & 23 & 25 & 27\end{array}$

Month

Figure 7 Change of the percentage of prescriptions including an injection from January 2016 to April 2018.

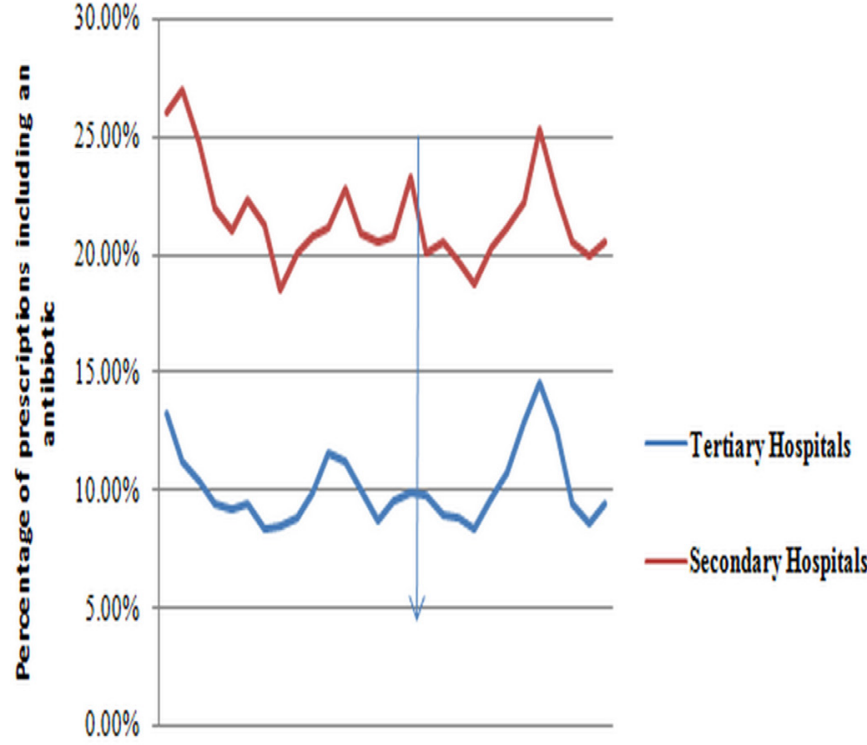

13579111315171921232527

Month

Figure 8 Change of the percentage of prescriptions including an antibiotic from January 2016 to April 2018.

intervention. After the intervention, the level of this indicator rose significantly $\left(\beta_{2}=0.044, \mathrm{p}<0.001\right)$, but the trend observed was consistent with that from before the intervention $\left(\beta_{3}=0.001, \mathrm{p}=0.684\right)$ (figure 7 , table 1$)$.

\section{Percentage of prescriptions that include an antibiotic}

As shown in figure 8 , the percentage of prescriptions that include an antibiotic showed substantial seasonal variation in tertiary hospitals, fluctuating between $8 \%$ and $16 \%$. There were no evident changes in the level or trend for this indicator in tertiary hospitals after implementation of the ZMDP.

In secondary hospitals, the percentage of prescriptions that include an antibiotic was also affected by seasonality, but the range of the fluctuation was smaller than that for tertiary hospitals. This indicator hovered at approximately $20 \%$ over the study period (figure 8 ).

\section{DISCUSSION}

This is the first quantitative study to use interrupted time series analysis to investigate the long-term effects of the ZMDP on rational drug use and drug expenditures in urban public secondary and tertiary hospitals in Western China.

Our study found that in both secondary and tertiary hospitals, trends for drug expenditures remained the same across the whole study period, but total medical expenditures rose abruptly after the intervention. He et $a l^{24}$ evaluated the impact of the ZMDP pharmaceutical reform on drug and total health expenditure in Sanming city and found similar results. In their analyses, drug and total health expenditures dropped sharply in the short term after implementation of the ZMDP but then 
increased over the longer term, with both indicators eventually exceeding their baseline levels.

In contrast, our study found that monthly drug expenditures and average outpatient drug expenditures did not decline after the ZMDP was implemented. This outcome may stem from the following two possible reasons. First, reduced drug prices may have prompted patients to choose more expensive drugs; thus, the absence of a decrease in outpatient drug expenditures may reflect patient choices. Second, while the policy removed the $15 \%$ profit on medications and successfully separated their sale from hospitals' other services, it did not affect kickbacks from drug companies to Chinese physicians. ${ }^{30} 31$ Thus, physicians' incomes were still related to hospital drug prescription patterns and costs. Our finding regarding the trend in drug expenditures suggests that further research is needed to understand changes in physician prescription behaviour or the use of other services in response to hospital drug pricing policies.

The ZMDP removed the $15 \%$ profit mark-up from drug sales and simultaneously raised fees for medical services to compensate for potential revenue loss. A study found that Chinese hospitals were able to offset the reductions made to drug revenues by increasing the provision of other profitable services or products. ${ }^{31}$ This pattern is another important factor that may explain the increases seen in medical expenditures following implementation of the ZMDP. Mao $e t a t^{25}$ analysed the impact of the ZMDP on rational use and affordability and found that the average medication expenditures per prescription did not change significantly between 2011 and 2013. However, Zhou et $a l^{32}$ assessed the effect of the ZMDP for essential drugs on medical expenses for patients at county hospitals and found that per-visit expenses for both outpatient and inpatient services were reduced after implementation of the ZMDP. These contrasting findings may stem from the differing in geographical areas and medical institution levels between the two studies.

For drug-related use, we found that from 2016 to 2018, the proportion of prescriptions that include an injection was always less than $20 \%$ in tertiary hospitals but over $20 \%$ in secondary hospitals. These findings may be related to differences in the knowledge level of the physicians and the patient population at these two types of hospitals. The tertiary hospital is a medical prevention technology centre with comprehensive medical, teaching and scientific research capabilities. Therefore, compared with secondary hospitals, tertiary hospitals have advanced facilities and a higher knowledge level of physicians. The rate of prescriptions for injections exhibited substantial seasonal variation in tertiary hospitals, and the rate of antibiotic prescribing fluctuated seasonally in both secondary and tertiary hospitals, reaching its highest level in the fourth quarter. Consistent with these findings, $\mathrm{Li}$ $e t a l^{33}$ also found that the overall percentage of antibiotic use temporarily increased in the winter. This pattern is likely related to the high incidence of respiratory diseases in winter. ${ }^{34}$
Our study also found that implementation of the ZMDP did not lead to any measurable changes in the rate of prescriptions for injections. Mao $e t a l^{25}$ found that the average number of medicines per prescription, the average number of antibiotics per prescription and the average number of injections per prescription decreased after implementation of the ZMDP. Chen $e t a l^{35}$ examined changes in drug use before and after implementation of ZMDP and found that the average outpatient medical expenditure per visit, the average outpatient drug expenditure per visit and the percentage of prescriptions that include an antibiotic all declined. Differences between these findings and our own may be due to the different geographical areas studied. There are many factors influencing the physician's prescription behaviour, including the patient's situation, the hospital's situation and the physician's own situation. Therefore, our results were different from other studies for many reasons. The patients in different regions may be different, the hospital performance may be different and the salary of clinicians in the western region may be lower than that of coastal developed regions. All of these may affect the final prescription behaviour of physicians, but it requires multicentre empirical research to corroborate.

We also found that the antibiotic prescription rate was below $16 \%$ in tertiary hospitals but was above $20 \%$ in secondary hospitals, which was a similar finding to that of our previous study on antibiotic prescribing practices from 2013 to $2015 .^{36}$ The Chinese government launched a national antibiotic stewardship action campaign in 2011 to promote the rational use of antimicrobial agents. ${ }^{37}$ This stewardship programme limit requires the rate of antibiotic prescription for outpatients in public hospitals to be less than $20 \% .^{38}$ Under the guidance of this principle, most hospitals began to implement the Antimicrobial Stewardship Programme (ASP) to promote the rational use of antibacterial agents. A large number of studies found that ASP has led to significant improvements in rational antibiotic use ${ }^{33} 3940$ thus suggesting that this type of programme is a necessary and effective way to improve future antimicrobial prescribing practices in China.

We found no significant correlation between the ZMDP and the antibiotic prescription rates in tertiary or secondary hospitals. This result may be because the use of antimicrobial agents in hospitals has decreased to a stable level following the implementation of the ZMDP. This finding differed slightly from those of a study conducted in county hospitals in China that found a significant reduction in the prescription of antibiotics after the implementation of China's essential medicine scheme and the ZMDP.

\section{Limitations}

Several limitations in this study should be considered. First, we conducted the study in one city; therefore, the results may not reflect the effects of the ZMDP throughout China. Future studies are needed to evaluate the longterm impacts of the ZMDP on health facilities throughout 
the country. Second, our research did not include primary care institutions, so we were unable to analyse differential effects of the policy on these institutions compared with secondary and tertiary hospitals. However, the implementation of the ZMDP policy in primary healthcare institutions is relatively recent, and other studies have evaluated the effect of this policy in Shaanxi primary healthcare institutions. ${ }^{32}$ Third, because of the limitations attached to the original prescription data, we did not analyse the rationality of each individual prescription. However, we compared our study results with national standards, which were designed by policy-makers taking into account the rational use of antibiotics. Finally, as we did not investigate the prescription behaviour of individual physicians, we cannot adequately explain the observed trends in drug expenditures. Future studies are needed to better understand the factors affecting physicians' prescription behaviour.

\section{CONCLUSION}

In summary, we found that the effect of the ZMDP reform on drug expenditures and drug use was not greatly evident. Future pharmaceutical reform measures should give more consideration to physician prescription behaviour to fundamentally reduce the medical burden on patients. At the same time, greater measures must be carried out to control the excessive and unnecessary use of injection drugs and antibiotics in hospitals.

Contributors Study design: KY, YF. Data collection: HZ, SL, JC, MJ, MZ. Data analysis: CY, DY. Supervision: KY, HZ. Writing original draft: KY, DY. Writing and editing: KY, CY, YF.

Funding This work was funded by the 'Young Talent Support Plan' and the 'High Achiever Plan' of the Health Science Center; Xi'an Jiaotong University and the Central University Basic Research Fund (2015qngz05); the National Natural Science Foundation of China (grant number 71603199); the Key Research and Development Planning Project of Shaanxi Province (2018SF-018) and the Key Research and Development Planning Project of Shaanxi Province (2019SF-198).

Competing interests None declared.

Patient consent for publication Not required.

Ethics approval Ethical approval was obtained from the Xi'an Jiaotong University Research Ethics Committee.

Provenance and peer review Not commissioned; externally peer reviewed.

Data availability statement № additional data available.

Open access This is an open access article distributed in accordance with the Creative Commons Attribution Non Commercial (CC BY-NC 4.0) license, which permits others to distribute, remix, adapt, build upon this work non-commercially, and license their derivative works on different terms, provided the original work is properly cited, appropriate credit is given, any changes made indicated, and the use is non-commercial. See: http://creativecommons.org/licenses/by-nc/4.0/.

ORCID iD

Caijun Yang http://orcid.org/0000-0001-6615-5425

\section{REFERENCES}

1 World Health Organization. The rational use of drugs. Report of the conference of experts. Geneva: WHO, 1985.

2 World Health Organization. Medicines use in primary care in developing and transitional countries: fact book Summarizing results from studies reported between1990 and 2006. Geneva: WHO, 2009.
3 World Health Organization. Medicines: rational use of medicines. WHO 2010.

4 Mao W, Vu H, Xie Z, et al. Systematic review on irrational use of medicines in China and Vietnam. PLoS One 2015;10:e0117710.

5 Kathleen H, Liset VD. The world medicines situation: rational use of medicines. Geneva: World Health Organization, 2010.

6 O'Neill J. Tackling drug-resistant infections globally: final report and recommendations. review on antimicrobial resistance 2016.

7 Costelloe C, Metcalfe C, Lovering A, et al. Effect of antibiotic prescribing in primary care on antimicrobial resistance in individual patients: systematic review and meta-analysis. $B M J$ 2010;340:c2096.

8 Hamblin S, Rumbaugh K, Miller R. Prevention of adverse drug events and cost savings associated with PharmD interventions in an academic level I trauma center: an evidence-based approach. $J$ Trauma Acute Care Surg 2012;73:1484-90.

9 Zhang M, Bian Y. Review of hospital medicines Mark-up policy and its impact. Health Service Management 2007;7:465-6.

10 Chinese Ministry of Health. Financial report of Medical institutions. Beijing, China, 2010.

11 Ministry of Health. China National health development research center. China National health accounts report. Beijing, China, 2009

12 Currie J, Lin W, Meng J. Addressing antibiotic abuse in China: an experimental audit study. J Dev Econ 2014;110:39-51.

$13 \mathrm{Li} \mathrm{Y,} \mathrm{Xu} \mathrm{J,} \mathrm{Wang} \mathrm{F,} \mathrm{et} \mathrm{al.} \mathrm{Overprescribing} \mathrm{in} \mathrm{China,} \mathrm{driven} \mathrm{by} \mathrm{financial}$ incentives, results in very high use of antibiotics, injections, and corticosteroids. Health Aff 2012;31:1075-82.

14 Zhang X, Wu Q, Liu G, et al. The effect of the National essential medicines policy on health expenditures and service delivery in Chinese township health centres: evidence from a longitudinal study. BMJ Open 2014;4:e006471.

15 Mao W, Chen W. The zero Mark-up policy for essential medicines at primary level facilities. background paper, China. 2015.

16 Zhou Z, Su Y, Campbell B, et al. The impact of China's Zero-Markup Drug Policy on county hospital revenue and government subsidy levels. Journal of Asian Public Policy 2015;8:102-16.

17 Deng J, Tian H, Guo Y, et al. A retrospective and prospective assessment of the zero-markup drug reform in China from the perspective of policy diffusion. Int $J$ Health Plann Manage 2018;33:e918-29.

18 Tao C, Bao G, Gao F, et al. Effect and suggestion of essential medicines system application on community health service institution. Prog Mod Biomedicine 2011;13:2551-4.

19 Jin C, Chen Z, He L, et al. The study on zero profit drug supply and the corresponding reimbursement policy in medical institutions in Shanghai. Chin J Health Policy 2010;3:24-8. In Chinese.

20 Yang C, Shen Q, Cai W, et al. Impact of the zero-markup drug policy on hospitalisation expenditure in Western rural China: an interrupted time series analysis. Trop Med Int Health 2017;22:180-6.

21 Cheng W, Fang Y, Fan D, et al. The effect of implementing "medicines zero mark-up policy" in Beijing community health facilities. South Med Rev 2012;5:53-6.

22 Wang J, Zhen J, Fan W, et al. Investigation and analysis of the effects of national essential drug system on medical expenses in different levels of medical institutions. Chin pharm 2013;23:2982-4. In Chinese.

23 Tian W, Yuan J, Yang D, et al. Descriptive analysis on the impacts of universal Zero-Markup drug policy on a Chinese urban tertiary hospital. PLoS One 2016;11:e0162795.

$24 \mathrm{He} \mathrm{Y,} \mathrm{Dou} \mathrm{G,} \mathrm{Huang} \mathrm{Q,} \mathrm{et} \mathrm{al.} \mathrm{Does} \mathrm{the} \mathrm{leading} \mathrm{pharmaceutical}$ reform in China really solve the issue of overly expensive healthcare services? Evidence from an empirical study. PLoS One 2018;13:e0190320.

25 Mao W, Huang Y, Chen W, et al. An analysis on rational use and affordability of medicine after the implementation of national essential medicines policy and zero Mark-up policy in Hangzhou, China. PLoS One 2019;14:e0213638.

26 Wei X, Yin J, Walley JD, et al. Impact of China's essential medicines scheme and zero-mark-up policy on antibiotic prescriptions in County hospitals: a mixed methods study. Trop Med Int Health 2017;22:1166-74.

27 Wagner AK, Soumerai SB, Zhang F, et al. Segmented regression analysis of interrupted time series studies in medication use research. J Clin Pharm Ther 2002;27:299-309.

28 Gillings D, Makuc D, Siegel E. Analysis of interrupted time series mortality trends: an example to evaluate regionalized perinatal care. Am J Public Health 1981;71:38-46.

29 The Statistical Yearbook in Xi'an, 2016. Available: http://tj.xa.gov.cn/ $\mathrm{ptl} / \mathrm{def} / \mathrm{def} / 2016 / \mathrm{zk} / \mathrm{indexch} . \mathrm{htm}$ [Accessed 2 Apr 2019].

30 Yip W, Hsiao WC. The Chinese health system at a crossroads. Health Aff 2008;27:460-8. 
31 Fu H, Li L, Yip W. Intended and unintended impacts of price changes for drugs and medical services: evidence from China. Soc Sci Med 2018;211:114-22.

32 Zhou Z, Su Y, Campbell B, et al. The financial impact of the 'zeromarkup policy for essential drugs' on patients in county hospitals in western rural China. PLoS One 2015;10:e0121630.

$33 \mathrm{Li} \mathrm{H}$, Yan S, Li D, et al. Trends and patterns of outpatient and inpatient antibiotic use in China's hospitals: data from the center for antibacterial surveillance, 2012-16. J Antimicrob Chemother 2019;74:1731-40.

34 Sofianopoulou E, Pless-Mulloli T, Rushton S, et al. Modeling seasonal and spatiotemporal variation: the example of respiratory prescribing. Am J Epidemiol 2017;186:101-8.

35 Chen T, Xie S, Wu R. Effect of drug price difference on rational drug use in public hospitals. Chinese Hospitals 2016;20:32-3. In Chinese.
36 Yan $\mathrm{K}, \mathrm{Xue} \mathrm{M}, \mathrm{Ye} \mathrm{D}$, et al. Antibiotic prescribing practices in secondary and tertiary hospitals in Shaanxi Province, Western China, 2013-2015. PLoS One 2018;13:e0207229.

$37 \mathrm{Ma} \mathrm{X}$, Xie J, Yang Y, et al. Antimicrobial stewardship of Chinese Ministry of health reduces multidrug-resistant organism isolates in critically ill patients: a pre-post study from a single center. BMC Infect Dis 2016;16:704.

38 National Health and Family Planning Commission of the People's Republic of China. Guiding Principles of Clinical Application of Antibacterials. Beijing 2015;7.

39 Zhou J, Ma X. A survey on antimicrobial stewardship in 116 tertiary hospitals in China. Clin Microbiol Infect 2019;25:759.e9-14.

40 Zhang D, Cui K, Wang T, et al. Trends in and correlations between antibiotic consumption and resistance of Staphylococcus aureus at a tertiary hospital in China before and after introduction of an antimicrobial stewardship programme. Epidemiology and Infection 2018:1-6 